\title{
AGENTES RURAIS E SUAS PRÁTICAS PROFISSIONAIS: ELO ENTRE MATEMÁTICA E ETNOMATEMÁTICA
}

\section{Rural agents and their professional practices: link between mathematics and ethnomathematics}

\author{
José Roberto Linhares de Mattos $^{1}$ • Maria Leopoldina Bezerra Brito ${ }^{2}$
}

Resumo: O trabalho trata da análise dos elementos da matemática e da etnomatemática em práticas agrícolas desenvolvidas em comunidades rurais, assistidas por técnicos agrícolas, denominados agentes rurais, que prestam assistência a essas comunidades. Através da observação das atividades praticadas por esses agentes em comunidades rurais do município de Crato, situado no estado do Ceará, procuramos identificar, nessa interação que ocorre entre o agente rural e o homem do campo, elementos da matemática e da etnomatemática. Discutimos as dificuldades no desempenho das tarefas dos agentes rurais, a necessidade do conhecimento de matemática nas suas atividades, e sua aprendizagem junto ao produtor rural, apontando caminhos essenciais para melhorar o ensino da matemática em sala de aula.

Palavras-chave: Agente rural. Comunidade rural. Etnomatemática. Ensino de matemática.

Abstract: This work is an analysis of the elements of mathematics and ethnomathematics in agricultural practices developed in rural communities, assisted by agricultural technicians, called rural agents, who provide assistance to these communities. Through observation of the activities practiced by these agents in rural communities in the Crato city, located in Ceara state, we identify in this interaction that exists between the rural agent and the peasant, elements of mathematics and ethnomathematics. We discussed the difficulties in fulfilling the tasks of rural agents, the need for knowledge of math in their activities and their learning with the farmer, pointing out key ways to improve the teaching of mathematics in the classroom.

Keywords: Rural agent. Rural community. Mathematics teaching. Ethnomathematics.

\footnotetext{
${ }^{1}$ Departamento de Geometria, Instituto de Matemática e Estatística, Universidade Federal Fluminense (UFF). Rua Mario Santos Braga s/n, Valonguinho. Niterói, RJ, Brasil.24.020-140.jrlinhares@gmail.com

${ }^{2}$ Instituto Federal de Educação, Ciência e Tecnologia do Ceará (IFCE), Campus Crato. Crato, CE, Brasil.
} 
Mattos, J. R. L.; Brito, M. L. B.

\section{Introdução}

A matemática constitui conhecimento que auxilia na compreensão do desenvolvimento da ciência, da tecnologia, e é presença constante na maioria das atividades humanas. Seja no trabalho, no lazer, no campo ou na cidade, estamos constantemente medindo, contando, calculando ou fazendo estimativas. Esses são alguns dos motivos por esta disciplina estar sempre em destaque no meio educacional. Fatos dessa natureza são observados em entrevistas de jornais, revistas ou televisão com estudantes ou professores. A matemática, normalmente, é citada pelos entrevistados, para demonstrar seu apreço ou rejeição, suas dificuldades ou facilidades no que diz respeito ao estudo desta disciplina, o que demonstra a influência do conhecimento desta ciência e quanto ela está presente no cotidiano. Conforme Schliemann (2006, p. 12), “[...] a matemática não é apenas uma ciência: é também uma forma de atividade humana", devendo, também, ser trabalhada na escola, o que nem sempre ocorre.

Observamos que as aulas de matemática são sempre recheadas de fórmulas e teorias, geralmente, descontextualizadas, desconsiderando, assim, a função social do ensino desta disciplina, causando desinteresse nos alunos. Verifica-se um trabalho bastante fragmentado, numa perspectiva ainda cartesiana, concebendo o conhecimento como algo desconexo dos outros saberes. Morin (2000), atenta-nos para o "recorte das disciplinas" que impossibilita, segundo ele, o que está "tecido junto". E vai mais longe ao afirmar que:

[...] A especialização "abs-trai”, em outras palavras, extrai um objeto de seu contexto e de seu conjunto [...] introduz o objeto no setor conceptual abstrato que é o da disciplina compartimentada, cujas fronteiras fragmentam [...] Conduz à abstração matemática que opera de si própria uma cisão com o concreto, privilegiando tudo que é calculável e passível de ser formalizado. (MORIN, 2000, p. 41-42)

Precisamos de um maior comprometimento, no trabalho, do professor para tentar construir no aluno a ideia de um sujeito investigativo, ampliando a compreensão de suas tarefas no mundo material e social, alargando seus horizontes para que se sinta realmente incluído no processo educacional.

Os atuais Institutos Federais de Educação, Ciência e Tecnologia são responsáveis pela formação dos técnicos agrícolas que participam do programa Agente Rural do governo do estado do Ceará. Estes técnicos são selecionados pela Empresa de Assistência Técnica e Extensão Rural do Ceará (Ematerce) e recebem bolsa de extensão rural. Exercem suas atividades junto aos produtores rurais de base familiar, prestando-lhes assistência técnica. O trabalho destes agentes rurais permite o encontro da matemática com a etnomatemática, fato que despertou o interesse pelo tema pesquisado.

Durante anos, trabalhamos no ensino agrícola e ensinamos matemática para muitos filhos de agricultores, sem conhecermos o contexto onde eles estavam inseridos. A realização desta pesquisa vem nos fornecendo elementos para que possamos eliminar dúvidas e angústias que, adquiridas ao longo dos anos, muitas vezes nos impediram de ajudar e compreender melhor os nossos alunos. Além disso, traz-nos, também, a oportunidade de rompermos com determinados paradigmas educacionais e assumirmos uma postura crítica em relação ao ensi- 
Agentes rurais e suas práticas profissionais: ...

no de matemática em sala de aula. Procuramos maneiras de superar os obstáculos encontrados no caminho do aluno e do professor, pois como afirma Freire (1996, p. 32): "Não há ensino sem pesquisa e pesquisa sem ensino".

Nossa questão de pesquisa é investigar, nas atividades dos agentes rurais que exercem suas atividades junto aos agricultores do município de Crato, CE, como se dá a interação entre a matemática utilizada por eles e a matemática utilizada pelo homem do campo, levando em consideração que os agentes rurais tiveram acesso ao conhecimento formal, já que tiveram formação técnica, no atual Instituto Federal de Educação, Ciência e Tecnologia do Ceará (IFCE), campus Crato, e que o agricultor, em sua maioria, não teve acesso a esse conhecimento, fazendo uso da matemática própria da sua cultura. Procuramos fazer uma análise dos elementos da matemática formal, em diálogo com os elementos da matemática do dia a dia do trabalhador rural. Nesta dinâmica, verificamos como ocorre a interação entre os agentes rurais e os agricultores, os dois tipos de matemática e a troca de conhecimentos nessa interação.

Examinando suas ações, procuramos identificar, no diálogo que acontece entre o agente rural e o produtor rural, elementos da matemática e da etnomatemática. Assim, fizemos uma análise do trabalho dos agentes rurais, no que concerne à matemática utilizada por eles e o tratamento dado à matemática utilizada pelo agricultor, buscando, no campo, soluções para os problemas da sala de aula, pois, de acordo com D'Ambrósio (2005, p. 22):

O cotidiano está impregnado dos saberes e fazeres próprios da cultura. A todo instante, os indivíduos estão comparando, classificando, quantificando, medindo, explicando, generalizando, inferindo e, de algum modo, avaliando, usando os instrumentos materiais e intelectuais que são próprios à cultura. Uma estratégia desenvolvida pela espécie humana ao longo de sua história para explicar, para entender, para manejar e conviver com a realidade sensível, perceptível, e com o seu imaginário, naturalmente dentro de um contexto natural e cultural.

Nessa discussão, entram, também, as concepções alternativas em relação à matemática, uma vez que é preciso valorizar os conhecimentos não formais, como caminhos de interação entre sujeitos sociais e historicamente determinados, envolvidos na dinâmica das relações sociais.

O trabalho no campo é rico em contextualização da matemática e em interdisciplinaridade, motivo que nos levou à escolha do tema pesquisado. As análises foram feitas com base nos princípios teóricos, levando em consideração princípios da etnomatemática. Trata-se de uma pesquisa com abordagem qualitativa. Como técnica de coleta de dados, utilizamos procedimentos advindos da etnografia: observação livre, depoimentos e entrevistas realizadas com os agentes rurais. Tal pesquisa vem confirmar a riqueza de saber que tem o homem do campo, quanto o seu conhecimento é importante na resolução dos problemas de sua comunidade ou grupo cultural, e a quantidade de conhecimentos que podemos adquirir com eles, para auxiliar professores e alunos no ensino e aprendizagem da matemática. 
Mattos, J. R. L.; Brito, M. L. B.

\section{Atitudes pedagógicas do ensino da matemática que dificultam a aprendizagem}

O baixo desempenho dos alunos em matemática é uma realidade em muitos países. Diante de tantos problemas por que passa a educação brasileira, a formação docente é apontada por pesquisadores como possibilidade de melhoria na aprendizagem desta disciplina. $\mathrm{O}$ que ocorre, geralmente, é a falta de reflexão sobre a matemática que está sendo estudada. Segundo Powell e Bairral (2006, p. 47), "aprendemos por meio de reflexões sobre nossa experiência", e essas não são trabalhadas com os alunos. Ainda de acordo com esses autores, "quando essa prática acontece, reflexões de outras pessoas são-lhes narradas e pede-se, simplesmente, que as memorizem" (POWELL; BAIRRAL, 2006, p. 48), o que acarreta graves consequências na aprendizagem. Esse problema didático também pode ser observado nas palavras de Pais (2002, p. 15):

Uma situação relativamente frequente no ensino da matemática é aquela em que o professor, ansioso por "solucionar" uma dificuldade de aprendizagem do aluno, acaba lhe fornecendo a solução completa do problema, impedindo sua participação na elaboração da resposta.

Sem perceber, o professor corta o raciocínio do aluno, impedindo-o de exercer seu poder de reflexão, sua autonomia e de fazer parte do processo educacional. Alunos e professores convivem com essa realidade e muitos parecem acreditar que a matemática é mais difícil ao ser comparada com outras disciplinas, e, assim, parecem ficar acomodados com essa ideia. Vários autores da educação e educação matemática buscam saída para essas dificuldades e defendem o ensino de matemática contextualizado. Para D’Ambrósio (1997, p. 120), “[...] aprender matemática não é o mero domínio de técnicas, de habilidades, nem memorização de algumas explicações e teorias"; e, segundo Freire (1996, p. 96), “[...] o fundamental é que professor e alunos saibam que a postura deles, do professor e dos alunos, é dialógica, aberta, curiosa, indagadora e não apassivada, enquanto falam ou ouvem".

A aprendizagem da matemática na sala de aula passa por um momento de interação entre a matemática organizada pela comunidade científica, conhecida como matemática formal, e a matemática como atividade humana.

\section{Etnomatemática como uma atitude pedagógica positiva que possibilita a contextualização do ensino da matemática}

Refletir sobre práticas pedagógicas positivas para o ensino de matemática em escolas agrícolas, essencialmente destinadas a atender a população oriunda de comunidades rurais, faz-nos voltar o olhar para a etnomatemática. O termo sugere uma mudança de postura e de metodologia no sentido de unir forças para melhorar o nível de aproveitamento em matemática, e, assim, tentar diminuir o índice de exclusão social.

$\mathrm{Na}$ matemática escolar, o aluno não vivencia situações de investigação, exploração, questionamento e reconstrução do processo educacional. Em decorrência disso, podemos 
Agentes rurais e suas práticas profissionais: ...

considerar trabalhos que apontam os progressos referentes ao uso de metodologias etnomatemáticas, como os da professora Gelsa Knijnik. Nas palavras da pesquisadora:

No âmbito da Educação Matemática, as idéias envolvidas na vertente da Etnomatemática vêm assumindo, nesta última década, um papel de destaque. O ICME-5 - 5th International Congresso on Mathematics Education - , realizado em Adelaide (Austrália), em 1984, pode ser considerado como um marco referencial do (re)conhecimento da Etnomatemática no cenário internacional. [...] Neste evento, a conferência inaugural "Sócio-cultural bases for Mathematics education" é dada por D`Ambrósio (1985). Nela, o educador discute a Educação Matemática na perspectiva da complexidade dos fatores sociais, e em particular, fatores educacionais presentes nos países periféricos, abordando um vasto conjunto de idéias que abrange desde o significado que dá à criatividade científica e o papel desta no avanço da ciência até questões mais amplas como as vinculadas à educação formal, e não-formal, que analisa, apoiado nas noções de códigos restritos e elaborados, de Basil Bernstein, e no posicionamento de Michel Foucault a respeito do papel do intelectual. (KNIJNIK, 2006, p. 125-126)

Na perspectiva da etnomatemática, é possível reconhecer que a matemática é uma disciplina dinâmica e viva, que reage como manifestação cultural e possibilita a quebra de silêncio dos alunos e dos professores:

A etnomatemática privilegia o raciocínio qualitativo. Um enfoque etnomatemático sempre está ligado a uma questão maior, de natureza ambiental ou de produção, e a etnomatemática raramente se apresenta desvinculada de outras manifestações culturais, tais como arte e religião. A etnomatemática se enquadra perfeitamente numa concepção multicultural e holística de educação. (D’AMBRÓSIO, 2005, p. 44)

É comum, em sala de aula, o aluno interromper o professor e indagar sobre a aplicação do conceito apresentado. A origem dessa pergunta pode estar no fato de o professor ter apresentado o assunto sem uma introdução histórica ou sem uma ligação do conteúdo, quer seja com as outras disciplinas, quer seja com as outras partes da própria matemática. Segundo D’Ambrósio (2005, p. 44), “[...] o essencial da etnomatemática é incorporar a matemática do momento cultural, contextualizada, na educação matemática".

Assim sendo, conhecer a realidade dos alunos e exercitar sua capacidade de argumentar, torna a sala de aula um lugar de descoberta, estimulada pelo debate, de forma a permitir que o estudo fique mais atraente e proveitoso. Esta é uma atitude pedagógica defendida pelos princípios da educação matemática na sua vertente etnomatemática, que deve ser adotada pelos educadores.

O trabalho do campo é repleto de saber matemático, dando-nos a oportunidade de atravessarmos as fronteiras da sala de aula, para conhecermos a realidade do nosso aluno e, 
Mattos, J. R. L.; Brito, M. L. B.

assim, compreendermos as dificuldades que eles enfrentam na escola, quando da aplicação dos conteúdos distanciados de seu contexto.

\section{Conteúdos de matemática inseridos no trabalho do agente rural}

Durante um ano, acompanhamos o trabalho dos agentes rurais no campo, para observarmos como utilizam a matemática em sua prática profissional nas comunidades rurais do município de Crato, CE. Estas observações ocorreram no período entre setembro de 2008 e setembro de 2009. Após esse espaço de tempo, foram realizadas as entrevistas com os seis agentes rurais pesquisados.

Tínhamos dois objetivos iniciais nesse intervalo de observações, além dos conteúdos de matemática aplicados no dia a dia desses profissionais. Um dos objetivos era o fato de ser muito importante conhecermos o trabalho do agente rural na prática, em seu cotidiano. Desta forma, estaríamos mais próximos desses trabalhadores, para que pudéssemos nos fazer confiantes e, assim, atingirmos o outro objetivo inicial, que era conseguirmos dados para a nossa pesquisa. Estávamos, então, preparando-nos para a realização das entrevistas, instrumento também utilizado em nossa coleta de dados. Segundo Marconi (2006, p. 96): "Quando o entrevistador consegue estabelecer certa relação de confiança com o entrevistado, pode obter informações que de outra maneira talvez não fossem possíveis".

\section{Operações básicas, unidades de medidas e proporção}

Ao relatarmos as atividades observadas, iremos destacar, em cada uma delas, um pouco dos conteúdos matemáticos observados. Verificamos que as operações básicas de adição, subtração, multiplicação e divisão, unidades de medidas, razão, proporção, regra de três, porcentagem, cálculo de área e estatística básica são conteúdos da matemática que aparecem, com frequência, em quase todas as atividades realizadas no trabalho desses profissionais.

Nossa primeira visita foi no dia 09 de setembro de 2008, quando os agentes rurais foram realizar o trabalho de vistoria de projeto nos sítios denominados de Trindade, Santa Fé e Brejinho, no município de Crato. Em cada uma dessas localidades, visitamos uma família de produtor, cuja principal atividade era a criação de gado de leite.

No trabalho de vistoria em projetos agropecuários, o agente faz as anotações no campo, por meio de coletas junto aos produtores. Posteriormente, as informações colhidas são repassadas para o laudo definitivo, em formulário padronizado para a finalidade.

Inicialmente, ele indaga ao produtor sobre a atividade financiada, o desenvolvimento dessas atividades e como estão sendo realizadas a produção e comercialização dos produtos. E, desta forma, ele confere e anota os dados para verificar se os recursos obtidos, através de projeto aprovado e financiado, foram aplicados corretamente pelo agricultor. Após a verificação da situação de produção agropecuária atual, chamado de "cenário de produção", ele faz as devidas orientações técnicas.

Nesse trabalho de vistoria, os conteúdos de matemática mais presentes são as operações básicas e as unidades de medidas, razão e proporção. 
Agentes rurais e suas práticas profissionais: ...

Verificamos parte do diálogo em que a matemática se faz presente, sendo que, em todo o nosso trabalho, iremos narrar os fatos sem utilizarmos os nomes verdadeiros dos sujeitos envolvidos, a fim de preservarmos a identidade das pessoas pesquisadas.

Apresentaremos, agora, situações dos dois primeiros sítios visitados nesse dia.

No primeiro sítio, chamado Trindade, distante $18 \mathrm{~km}$ do centro da cidade, o agente rural Carlos indaga a Sra. Vanda a respeito da produção do leite das três matrizes bovinas que foram financiadas com recursos oriundos do Programa Nacional de Fortalecimento da Agricultura Familiar (Pronaf). Vejamos o diálogo entre o agente e o produtor:

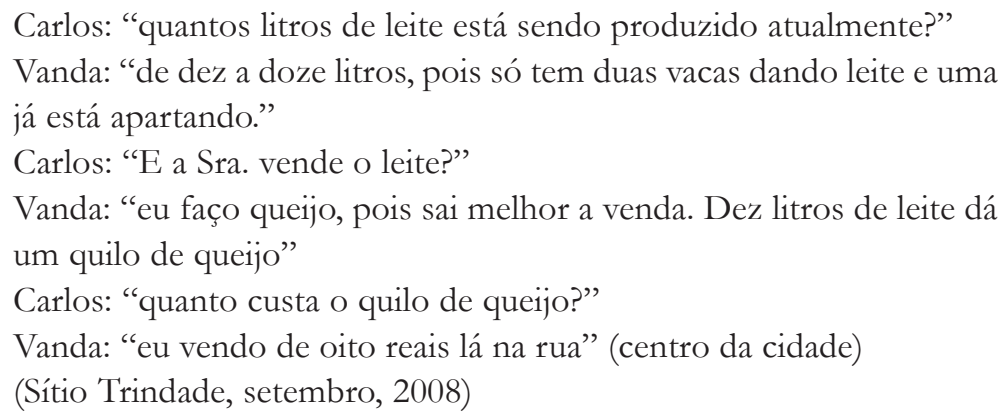

Assim, o agente faz uma análise do cenário atual da produção e condução das atividades realizadas pelo agricultor. Após o registro de todos os dados, o laudo irá informar a situação do produtor, que pode ser negativa ou positiva. Ele aplica as operações básicas da matemática, por exemplo, para estimar o rendimento mensal da parte do leite: multiplica o preço do quilo do queijo, que foi de $\mathrm{R} \$ 8,00$, pela quantidade de dias correspondentes a um mês, trinta dias, e assim, obtém $\mathrm{R} \$ 240,00$ referente à renda bruta mensal pelo derivado do leite.

$\mathrm{Na}$ continuação do trabalho, observamos quando o agente conferiu, "em passos largos", a área do galpão destinado à criação de pintos, que se encontrava vazio no momento. Ele fez o cálculo da seguinte forma: contou cinco passos para um lado e mais cinco para o outro lado perpendicular àquele, e, assim, conferiu a área correspondente a $5 \mathrm{~m} \times 5 \mathrm{~m}=25 \mathrm{~m}^{2}$. Em seguida, orientou a limpeza do galpão, para desinfecção, da seguinte forma: passar a cal nas paredes e colocar formol em todo o galpão, de acordo com a medida do aviário; colocar o produto em proporções adequadas, evitando danos futuros, e que, somente após esses procedimentos, poderia ser colocado um novo lote de duzentos e cinquenta pintos.

Em relação à dosagem de vacina dos animais, as proporções são importantes nas orientações repassadas. $\mathrm{O}$ agente ajuda o produtor a seguir as proporções indicadas na bula do medicamento utilizado. As indicações, normalmente, são de acordo com o peso do animal e, muitas vezes, há necessidade de uma demonstração prática feita pelo agente, para que o produtor aprenda a vacinar. Por exemplo, existe medicamento em que a bula orienta $1 \mathrm{ml}$ para cada quilo de peso; outro já pode indicar $10 \mathrm{ml}$. Normalmente, os agentes fazem uma demonstração prática para o produtor: no caso de injetável, caso o produtor não domine leitura, os agentes indicam, na seringa, o equivalente a $1 \mathrm{ml}$ ou $2 \mathrm{ml}$, apontando o dedo na parte respectiva, e ainda fazem as primeiras vacinações ensinando ao produtor para que eles aprendam.

O agente Carlos explica, em entrevista realizada dia 28 de dezembro de 2009, o que acontece na prática em relação à dosagem e aplicação do vermífugo em ovinos, por exemplo: 
Mattos, J. R. L.; Brito, M. L. B.

Leo (pesquisador): "Primeiro os vermífugos, quais são as dosagens?" Carlos: "O vermífugo é o seguinte: vai variar depende muito do tipo, do laboratório e eles vem na bula, né? A maioria vem na bula, e, é bem interessante, porque a gente faz criteriosamente mediante a quantidade de quilo de peso vivo $1 \mathrm{ml}$ para cada quilo de peso vivo e é bem interessante é, as "artimanhas" deles que a gente faz uma bem rigorosa mesmo, uma com ele, ensinando a ele, e...as vezes a gente deixa eles fazerem as outra vezes e eles, eles quando é...as vezes você chega lá e eles estão fazendo, interessante eles pegam os animais que têm uma aproximação de peso e aplica a mesma dosagem, $1 \mathrm{ml}$ para animais que oscilam entre 18 a 20 quilos de peso vivo, se $1 \mathrm{ml}$ é para cada 20 quilo de peso vivo, eles fazem, onde a gente também sabe que não é, não é tão, isso não é tão prejudicial porque o vermífugo, ele não pode dá uma super dosagem, mas também não pode aplicar menos pelo fato de que ele não atinge o objetivo de eliminação do parasita, né? Mas ele seleciona animais de determinado peso e aplica $1 \mathrm{ml}, 20 \mathrm{ml}$ para cada 20 quilos de peso vivo, eles pegam animais de 18 a 22 quilos e aprende isso, é coisa natural do produtor de ovinocaprinocultura, eles fazem isso de maneira bem, bem racional, com inocente mas que tem resultados proveitosos."

(Entrevista 3, dezembro, 2009)

A importância do conhecimento teórico e prático do agente rural e a prática da atividade realizada por eles tornam a aprendizagem mais significativa para os agricultores e, em seguida, eles fazem as devidas adaptações para resolverem o problema da forma mais prática. Os agricultores, ao separarem o rebanho pela média aproximada do peso, facilitam a prática do trabalho, o que não compromete a qualidade dos resultados esperados, conforme afirma o agente rural Carlos em sua fala, veja na continuação dessa entrevista:

Leo: "Deixe ver se eu entendi? são quantos $\mathrm{ml}$ para cada?"

Carlos: "Digamos que $1 \mathrm{ml}$ seje para vinte quilos de peso vivo, eles pegam animais de categoria de peso entre 18 e 22, separam num só rebanho e aplicam $1 \mathrm{ml}$ só pra esses animais, inocentemente mas só que a gente sabe que também dá resultado, não pode dá super dosagem, mas também não pode dá menos porque não atinge o objetivo principal pra eliminação do parasita, né?” (Entrevista 3, dezembro, 2009)

Assim, o uso das proporções, das operações básicas e das unidades de medida serve ao homem do campo em suas atividades diárias: elas são utilizadas e vão fazendo parte de cada momento no trabalho do agente rural, firmando-se em suas orientações e observações. Há sempre um raciocínio matemático e um cálculo a ser efetuado, uma unidade de medida seja de comprimento, volume ou massa - a ser utilizada, onde a aprendizagem se confirma na prática, em que há uma razão de ser desses conteúdos, o que pode reforçar a existência destes nos currículos escolares. 
Agentes rurais e suas práticas profissionais: ...

\section{Estatística básica, unidades de medidas e operações básicas}

No dia 21 de novembro de 2008, acompanhamos uma biometria realizada no Sítio Araças. O Produtor Nelson fez um projeto inicial para criação de oitocentas tilápias (Oreochromis niloticus), sob o acompanhamento da Ematerce. Os agentes rurais participam do mesmo desde a construção do tanque até a comercialização dos peixes. Assim, acompanhamos os agentes Carlos e Magno nessa tarefa de realizar a quinta biometria e repassar as técnicas para o jovem produtor, Nelson.

Com o material necessário para realizar a biometria - uma balança, uma tábua com régua em centímetros, a rede para pescar as amostras de tilápias e um recipiente com água -, seguimos até o tanque onde se encontravam as tilápias de três meses.

Nelson pegou a rede, pescou as amostras e colocou no recipiente com água. Somente com água o recipiente pesou $3 \mathrm{~kg}$. Depois de colocadas as oito amostras pescadas, pesaram o balde novamente, obtendo $5,620 \mathrm{~kg}$. Feita a diferença entre os pesos, a massa dos 8 peixes foi de $2,620 \mathrm{~kg}$, o que deu uma média de $327,5 \mathrm{~g}$ de massa por peixe. Após a pesagem, eles mediram o tamanho de cada tilápia - uma por uma - e, assim, registraram: $23 \mathrm{~cm} ; 25,5 \mathrm{~cm} ; 26$ $\mathrm{cm} ; 25 \mathrm{~cm} ; 22 \mathrm{~cm} ; 23 \mathrm{~cm} ; 23 \mathrm{~cm} ; 21 \mathrm{~cm}$. Devolvendo as amostras ao tanque, os agentes Carlos e Magno, juntamente com Nelson, iniciaram os cálculos. Toda orientação fora repassada ao produtor para que ele aprendesse o trabalho, ficando, assim, independente, futuramente.

Iniciando pelo cálculo da média aritmética das amostras, tudo foi feito com o auxílio de uma calculadora.

Calculando a média: $23+25,5+26+25+22+23+23+21=188,5 \div 8=23,56$ $\mathrm{cm}$. Comparada com a média anterior, que foi de $20,6 \mathrm{~cm}$, significou que os peixes aumentaram de tamanho, em média, em: 23,56 cm $-20,6 \mathrm{~cm}=2,96 \mathrm{~cm}$. Registrou-se, então, nas anotações dos agentes, o valor aproximado de três $\mathrm{cm}$ de aumento. A massa de 327,5 g foi multiplicada por 800 (quantidade de peixe do tanque) sendo o cálculo realizado pelo agente rural: $327,5 \mathrm{~g} \times 800=262000$. Nesse momento, observamos um pequeno desconcerto dos agentes, pois eles queriam a resposta em quilograma e observaram que encontraram um número elevado: 262000. Foram rever os cálculos e entenderam que a unidade de massa com que estavam trabalhando era o grama, então, teria de ser transformada para quilograma. Resolvido o impasse, "dividiram na calculadora”, 262000 por mil e anotaram $262 \mathrm{~kg}$.

Dando continuidade, eles calcularam $4 \%$ de $262 \mathrm{~kg}$, fazendo uso da calculadora, da seguinte forma: $262 \times 0.04=10,48 \mathrm{~kg}$. O percentual de $4 \%$ foi o indicado na tabela de crescimento e engorda dos peixes de acordo com o tamanho e idade dos alevinos. Assim, o valor obtido foi arredondado para 10,5 kg e corresponde à quantidade diária de ração a ser colocada para os peixes. O agente orienta o jovem a colocar, a partir daquele dia, 10,5 kg de ração, que será distribuída em três vezes, sendo: $10,5 \div 3=3,5 \mathrm{~kg}$ por vez, a cada cinco horas de um dia de 12 horas. O agente rural deixa, assim, determinados, os horários de: sete horas, 12 horas e 17 horas para colocar a ração durante os 15 dias seguintes até a próxima biometria.

A riqueza de cálculos que esse trabalho apresenta pode ser entendida de forma simples quando associada à sua prática, o que nem sempre acontece nas salas de aula ao se trabalhar uma atividade semelhante no quadro, simulando uma situação real.

É possível observar que cada detalhe da atividade envolve um saber matemático. Ao pesar a água no recipiente para colocar o peixe, é usada a unidade de medida de massa, que é 
Mattos, J. R. L.; Brito, M. L. B.

o quilograma. Ao pesar o recipiente com água e, depois, com as amostras, é realizada a subtração para saber o peso das amostras, também em quilograma. Ao realizar a medição das amostras, é utilizada uma unidade de medida de comprimento, que é o centímetro. A adição e a divisão são utilizadas para o cálculo da média de tamanho das amostras. Para encontrar a biomassa do tanque, é usada a multiplicação da média pelo total de peixes do tanque, que vai representar a biomassa do tanque $(262 \mathrm{~kg})$. O conteúdo de porcentagem aparece quando ele vai calcular o percentual, no caso, $4 \%$, que aplicado à biomassa (peso vivo de peixes no tanque) vai representar a quantidade de ração diária consumida pelos peixes. A divisão do dia de 12 horas e da massa da ração, por três, para obter a quantidade a ser colocada no tanque, por vez, trabalha novamente uma operação básica da matemática.

Essa atividade também nos chamou a atenção pela quantidade de conteúdos que ela é capaz de reunir. Não apenas os conteúdos de matemática, ela reúne uma diversidade de conteúdos de outras disciplinas que são trabalhadas em nossos Institutos, tanto no Ensino Médio, como química, física, biologia, geografia, quanto no ensino profissionalizante, como agricultura, piscicultura, construções e instalações rurais e zootecnia.

Como forma de sugestão da nossa pesquisa para melhoria na qualidade do ensino Técnico Agropecuário e partindo da atividade relatada anteriormente, podemos pensar, por exemplo, em um projeto interdisciplinar de criação de peixes que pode ser desenvolvido nos Institutos Federais de Educação, Ciência e Tecnologia, que trabalham na formação de Técnicos Agrícolas. Nossas escolas possuem estrutura física capaz de desenvolver um projeto desta natureza, envolvendo professores, alunos e toda a comunidade escolar. Assim sendo, reforçase a capacidade do exercício da função que lhe é atribuída na formação profissional para melhor atingir o objetivo pedagógico de ensinar e aprender de maneira prática e consciente, observando e fazendo, pois, ao se fazer, consegue-se entender; entendendo-se, consegue-se explicar. É isso que estimula e transforma a teoria em ação, aplicando o conhecimento em prática refletida e planejada. Conforme D’Ambrósio (1997, p. 20, grifos do autor): "Essa ação se dá mediante o processamento de informações captadas da realidade", a ação gera o matema, conhecimento e capacidade de explicar, de lidar de manejar, de entender a realidade.

Nesse sentido, poderíamos ter uma maior aproximação entre os Institutos Federais de Educação, Ciência e Tecnologia e as Empresas de Assistência Técnica e Extensão Rural (Emater), a exemplo do Instituto Federal de Educação, Ciência e Tecnologia de Brasilia (IFB), campus Planaltina. Lá existe um Centro de Treinamento da Emater-DF, dentro do Instituto, em espaço cedido pelo mesmo, onde há uma maior interação entre as partes, cujos técnicos ministram cursos para os alunos na área de agroindústria e para toda a comunidade. Também são ofertados vários outros cursos pela empresa, como o "vaqueiro competente", por exemplo, que é ofertado para pessoas da comunidade. Na medida em que os alunos não precisam buscar estágio em empresas distantes, eles podem realizá-lo dentro do próprio Instituto, por meio do Centro de Treinamento da Emater-DF.

Assim, os Institutos Federais de Educação, Ciência e Tecnologia estariam transmitindo e acumulando conhecimento no convívio com as outras pessoas, e fazendo isso de forma "duplamente" produtiva, no sentido de produzir conhecimento e produzir alimento.

Em nossas entrevistas, indagamos aos agentes rurais sobre quais as sugestões dadas por eles para melhorar o ensino de matemática na formação do técnico agrícola. Vejamos os resultados: 
Agentes rurais e suas práticas profissionais: ...

Leo: "pela sua experiência profissional, que sugestão você tem para melhorar o ensino de matemática na formação do técnico agrícola?"

Carlos: "Maior integração da matemática com as áreas agropecuária, trabalhar cálculos que simule muito mais a realidade de campo." (Entrevista 3, dezembro, 2009)

Bosco: "Aulas mais práticas com demonstrações em campo." (Entrevista 4, dezembro, 2009)

Silvia: "Na minha opinião seria elaborar questões vivenciadas na zona rural, como cálculo de área por exemplo." (Entrevista 6, fevereiro, 2010) Magno: "Através de práticas efetuadas no campo, cálculos que envolvam a atividade trabalhada pelo homem do campo, como: dimensionamento de um silo para silagem." (Entrevista 1, novembro, 2009)

Ana: "Adequar o conteúdo da matemática voltado mais para o meio rural.” (Entrevista 5, dezembro, 2009)

César: "Uma matemática simples e objetiva." (Entrevista 2, novembro, 2009).

As respostas dadas pelos agentes rurais em relação à pergunta feita confirmam a teoria de que a contextualização dos conteúdos é uma das saídas para superação das dificuldades na aprendizagem. Sendo assim, um ensino conectado com as aplicações práticas dos conteúdos vai tornar a sala de aula um ambiente de aprendizagem bem mais atraente para o aluno, compreendendo que, não necessariamente, ou nem sempre, a sala de aula deve ser aquele ambiente entre quatro paredes e em uma escola.

\section{O agente rural e a matemática em situações do cotidiano}

Notamos que o cálculo de área no meio rural é muito utilizado, já que os agricultores separam as terras para cultura do arroz, do feijão, do milho, fazem canteiros de hortas e outras. Porém, as unidades de medidas utilizadas por eles não são encontradas em livros didáticos de matemática. Em muitas situações, valem-se de recursos não formais para medidas de comprimento, como o "palmo" e a "braça", além de utilizarem a "tarefa" para medir área. O que podemos observar, a partir daí, é que, apesar de esses conhecimentos atenderem a demanda do agricultor, ainda que imediata, não contam com o respaldo científico, ficando, portanto, à margem do conhecimento acadêmico. Nesse sentido, o técnico agrícola, ao iniciar seu trabalho no campo, aprende com o agricultor esses elementos que lhes são próprios e passa a utilizá-los para que haja uma melhor interação entre eles. Podemos confirmar isso nas palavras do agente rural que denominamos de Carlos. Ele diz: "Leo, no campo é só o que agente usa, é tarefa, é braça, é palmo".

Em ocasião de uma de nossas visitas, obtivemos um depoimento surpreendente de dois desses profissionais, em relação a uma dificuldade enfrentada por eles, referente ao uso da matemática em sua prática. Fato este que revela uma situação da didática da matemática, faz-nos refletir e nos incentiva, ainda mais, na realização da pesquisa. 
Mattos, J. R. L.; Brito, M. L. B.

Os autores do depoimento têm mais de dois anos de trabalho como técnicos agrícolas e serão chamados aqui de Carlos e Magno. O fato foi narrado por Carlos e confirmado por Magno, da seguinte forma:

Carlos: "Leo, eu passei a maior vergonha quando um agricultor pediu pra mim, "Carlos, marque aqui uma tarefa de terra pra eu plantar". A primeira coisa que eu pensei, Leo, foi em um terreno com $55 \mathrm{~m}$ por $55 \mathrm{~m}$ para dar $3025 \mathrm{~m}^{2}$ que é só o que a gente vê na escola, mas como eu ia fazer o cálculo se a largura da terra não dava isso? Ai, Leo, eu me aperriei, fiquei puxando a trena e demorando, demorando... pense num sufoco! Mas o mês passado, um engenheiro me ensinou um jeito tão fácil que eu nunca vi ninguém fazer daquele jeito, olha Leo eu sei que tu sabe, mas eu vou te dizer como é só para tu vê. É assim, o engenheiro me ensinou e eu passei para Magno que também não sabia. Você pega, vamos supor, você calcula aqui a cabeça do terreno (referindo-se a largura) e mede, por exemplo, mediu vinte metro; agora é só você pegar 3025 e dividir por vinte, que você vai ter a medida que você quer e isso vale para qualquer medida de "cabeça" que você pegar. Olha, Leo, isso foi bom demais, agora eu não tenho mais medo, pode pedir qualquer quantidade que eu sei fazer a conta."

Toda narrativa foi confirmada por Magno, que também confessou ter passado pela mesma dificuldade.

Em situação semelhante, outro agente rural, em ocasião do trabalho para medir a área do terreno onde seria plantado milho, na comunidade do sítio Palmeirinha, demonstrou a mesma dificuldade. Para narrar o fato, vamos chamar esse agente de César.

O terreno tem forma retangular e uma área de 5 tarefas, estimada pelo agricultor. César inicia a medida, com a ajuda do agricultor puxa a trena, medindo 32 metros de largura; em seguida, pega uma calculadora para encontrar o comprimento que multiplicado pela largura corresponda a uma tarefa, ou seja, $3025 \mathrm{~m}^{2}$. César faz os seguintes cálculos na calculadora: $32 \times 100=3200 ; 32 \times 90=2880 ; 32 \times 95=3040 ; 32 \times 94=3008$. O valor que ele queria é facilmente encontrado realizando a operação de divisão: $3025 \div 32=94,53$ metros.

As duas situações do cotidiano do agente rural nos remeteram a fazer uma reflexão sobre a nossa prática, enquanto professor de matemática, e a subscrevemos aqui nas palavras de Schliemann (2006, p. 12): "A aprendizagem de matemática na sala de aula é um momento de interação entre a matemática organizada pela comunidade científica, ou seja, a matemática formal, e a matemática como atividade humana". Não podemos separar as duas formas, negando, ao nosso aluno, a matemática como atividade humana, porém é necessário contextualizar, de forma que o ensino seja completo. No entender de D’Ambrósio (2005, p. 76), “[...] se quisermos atingir uma sociedade com equidade e justiça social, a contextualização é essencial para qualquer programa de educação de populações nativas e marginais, mas não menos necessária para as populações dos setores dominantes". 
Agentes rurais e suas práticas profissionais: ...

\section{Elementos da matemática e da etnomatemática na dinâmica do trabalho do agente rural}

Acompanhamos um levantamento feito no Sítio Inchu, na propriedade arrendada pelo senhor que aqui vamos chamar de José, pelos mesmos agentes que chamamos de Carlos e Magno. Nesse trabalho pudemos observar o diálogo entre a matemática e a etnomatemática. Ao chegarmos próximos ao cacimbão que há na propriedade, verificamos parte do diálogo:

Carlos pergunta ao Sr. José: “Quantos 'metros' tem a 'boca' dessa cacimba?" Sr. José responde: "tem mais de onze 'palmo'.

Carlos diz a Magno (que estava com a calculadora em mãos): "Faz aí, Magno, vinte e dois vezes onze".

Magno faz o cálculo e diz: "dá duzentos e quarenta e dois"; em seguida Carlos faz a aproximação para 2,5 metros e anota. (Sítio Inchu, janeiro, 2009)

O diálogo permite percebermos a matemática utilizada pelo agricultor e a matemática utilizada pelo agente rural. Observamos que, quando o agente faz a pergunta: quantos "metros"? (unidade de medida padrão da matemática formal), o produtor responde em palmos, elemento de sua cultura. O agente utiliza o termo "boca" se referindo ao diâmetro da cacimba. Acreditamos ser um conhecimento que ele adquiriu da cultura do produtor, pois se ele utilizasse o termo da matemática formal - diâmetro - dificilmente seria entendido pelo produtor. Assim se dá a troca de aprendizagem entre os sujeitos. Segundo D’Ambrósio (1990, p. 35): “A passagem da etnomatemática para a matemática pode ser vista como a passagem da linguagem oral para escrita", o que nos leva a perceber que o conhecimento etnomatemático precede o conhecimento matemático. Ainda, segundo D’Ambrósio (1990, p. 35):

[...] As práticas etnomatemáticas ainda estão desvalorizadas no sistema escolar, em todos os níveis de escolaridade e até mesmo na vida profissional, e algumas vezes levam a humilhação e são, na maioria dos casos, consideradas irrelevantes para o conhecimento matemático.

Pudemos observar que, a todo instante, o agente realizava conversões das medidas utilizadas pelo agricultor. Conforme vimos, a conversão do palmo para o centímetro e do centímetro para o metro, faz-nos constatar a necessidade do conhecimento da matemática formal para finalização dos trabalhos do agente rural, pois os formulários da Ematerce são todos preenchidos de acordo com os conhecimentos da matemática acadêmica.

Observe os trechos de nossas entrevistas e as respostas dadas pelos agentes rurais sobre o conhecimento etnomatemático do homem do campo. Veja que, nessa dinâmica de interação, há sempre uma troca de experiência/aprendizagem entre os sujeitos envolvidos:

Leo: "Ainda que não tenha o conhecimento acadêmico, o homem do campo possui uma maneira própria de fazer suas contas. Em seu coti- 
Mattos, J. R. L.; Brito, M. L. B.

diano você já aprendeu algum tipo de matemática com o produtor rural?"

Ana: "Sim, a gente aprende várias coisas, entre elas a que achei de grande importância foi transformar léguas (quadradas) em hectares, em tarefas." (Entrevista 5, dezembro, 2009)

Magno: "Sim, o uso de unidades de medidas como tarefas, palmos, e uso de pesagem de sacos de milho, feijão..."

Leo: "Como é que eles pesam? Dê um exemplo."

Magno: "Eles pesam, às vezes eles pesam no olho, eles enche a saca e dependendo do grão, eles sabem o peso pelo olho, mais ou menos o tamanho do saco e sabe se já tem sessenta quilo, por exemplo. Que eles já tem costume de fazer isso aí sabe, né? se a pessoa for conferir é bem aproximado mesmo." (Entrevista 1, novembro, 2009)

Bosco: "Foi que um dia eu fui medir uma área aí eu não tinha a trena grande de cinquenta metros, aí eu levei uma pequena pra medir uma braça, fui com o produtor aí tirei a braça aí eu medi, né? Quando eu medi, aí ele foi e disse deixa eu ver se sua braça tá certa, aí, pegou ela e esticou, levantou a mão assim e esticou e botou três dedos e disse tá certa, minha braça é desse jeito, eu meço desse jeito e tá certo." (Entrevista 4, dezembro, 2009)

Existem, junto aos agricultores, as mais variadas formas de trabalhar com medidas de comprimento - a légua, a braça, o passo, o pé, o palmo, a polegada -, que, desde as maiores até as menores distâncias, são unidades comuns aos agricultores. $\mathrm{O}$ agente rural, ao realizar suas tarefas no campo e utilizar os elementos matemáticos da cultura do agricultor, faz com que o agricultor fique atento e chegue, até mesmo, a conferir as medidas, como foi o caso contado pelo agente Bosco na entrevista acima citada.

Assim, a matemática do cotidiano serve ao homem do campo, porque suas estimativas são bem aproximadas. Vimos que o diálogo acontece sem maiores dificuldades, na medida em que o agente rural já absorveu muitos elementos da cultura do produtor e aprendeu com ele. Nessa interação, os dois conhecimentos são importantes e se completam, podendo ajudar muito a professores e alunos, se forem observados os princípios ideológicos da etnomatemática no ensino da matemática.

\section{Considerações finais}

A inspiração para o trabalho ocorreu em função de uma trajetória docente na antiga Escola Agrotécnica Federal de Crato, e é parte de uma dissertação de mestrado em Educação Agrícola na Universidade Federal Rural do Rio de Janeiro, defendida em maio de 2010.

Observando as atividades realizadas pelos agentes rurais no campo, constatamos quais conteúdos matemáticos são mais utilizados por esses técnicos agrícolas que realizam o trabalho de extensão rural. Com isto, foi possível refletir sobre a nossa prática educativa, em que pudemos nos colocar na condição de alunos e pensar nas dificuldades que eles enfrentam ao 
Agentes rurais e suas práticas profissionais: ...

chegarem à escola e encontrarem um ensino de matemática que não condiz com a sua realidade. Fato este que nos levou à "descoberta do outro", necessariamente pela "descoberta de si mesmo".

Por meio de entrevistas, observações e depoimentos, detectamos algumas dificuldades enfrentadas pelos agentes rurais, quando na aplicação de determinados conteúdos matemáticos. Constatamos que isto ocorre em consequência de um ensino de matemática descontextualizado. Assim, confirma-se o fundamento de que, por meio da realização de atividades práticas, a aprendizagem se torna mais significativa para o aluno, ocasião em que se pode perceber a razão de ser e de existir dos conteúdos nos currículos escolares.

Vimos que, na dinâmica de interação do trabalho do agente junto ao produtor rural, prevalecem os elementos matemáticos da cultura do homem do campo, em que são utilizados alguns meios próprios para fazer os cálculos, como os defendidos na perspectiva etnomatemática. Por conseguinte, chegamos à crença de que é importante a inclusão do estudo de matemática levando em consideração tal perspectiva. O conhecimento etnomatemático está envolvido nesse trabalho e, assim, constatamos a troca de conhecimento entre agente e produtor rural, também por meio de suas experiências.

Constatamos que as atividades realizadas pelos agentes e produtores rurais podem servir de auxílio, na prática da interdisciplinaridade, para os professores. Vimos que, por meio de uma atividade prática do trabalho do agente rural, é mais fácil perceber a ligação que existe entre as disciplinas, o que pode ajudar tanto o professor quanto o aluno, nas aulas de matemática, a superarem seus limites.

Sendo assim, esperamos que este trabalho contribua para a prática da contextualização e da interdisciplinaridade na escola, auxiliando professores e alunos na busca pelo saber matemático consciente, criativo e reflexivo, ou seja, uma educação que construa cidadania. E que, também, possa impulsionar a continuação desta e a elaboração de outras pesquisas, a fim de obter outros caminhos metodológicos que auxiliem a educação matemática, pois sabemos que ainda há muito conteúdo a ser explorado nesse campo para melhorar, cada vez mais, o ensino e a aprendizagem desta ciência na prática educacional.

\section{Referências}

D’AMBRÓSIO, U. Etnomatemática: elo entre as tradições e a modernidade. 2. ed. Belo Horizonte: Autêntica, 2005.

Educação matemática: da teoria à prática. 2. ed. Campinas: Papirus, 1997.

Etnomatemática. São Paulo: Ática, 1990. (Série Fundamentos).

FREIRE, P. Pedagogia da autonomia: saberes necessários à prática educativa. São Paulo: Paz e Terra, 1996.

KNIJNIK, G. Educação matemática, culturas e conhecimento na luta pela terra. Santa Cruz do Sul: EDUNISC, 2006. 
Mattos, J. R. L.; Brito, M. L. B.

MARCONI, M. A.; LAKATOS, E. M. Técnicas de pesquisa: planejamento e execução de pesquisas, amostragens e técnicas de pesquisas, elaboração, análise e interpretação de dados. 6. ed. São Paulo: Atlas, 2006.

MORIN, E. Os sete saberes necessários à educação do futuro. 2. ed. São Paulo: Cortez; Brasília: Unesco, 2000.

PAIS, L. C. Didática da matemática: uma análise da influência francesa. 2. ed. Belo Horizonte: Autêntica, 2002.

POWELL, A.; BAIRRAL, M. A escrita e o pensamento matemático: interações e potencialidades. Campinas: Papirus, 2006.

SCHLIEMANN, A. D.; CARRAHER, D. W.; CARRAHER, T. N. Na vida dez, na escola zero. 14. ed. São Paulo: Cortez, 2006.

Artigo recebido em 12/12/2011. Aceito em 09/08/2012. 